\title{
Genetically Engineered Mesenchymal Stem Cells Influence Gene Expression in Donor Cardiomyocytes and the Recipient Heart
}

\author{
Mary Kearns-Jonker ${ }^{1,4 *}$, Wangde Dai ${ }^{2}$, Mirja Gunthart ${ }^{1}$, Tania Fuentes ${ }^{4}$, Hsiao-Yun Yeh ${ }^{4}$, Paul Gerczuk $^{2}$, Martin Pera $^{3}$, Christine Mummery ${ }^{5}$ \\ and Robert A Kloner ${ }^{2,3}$
}

${ }^{1}$ Dept of Cardiothoracic Surgery, Childrens Hospital Los Angeles, Los Angeles, CA, USA

${ }^{2}$ Heart Institute of Good Samaritan Hospital, Los Angeles, CA, USA

${ }^{3}$ Eli and Edythe Broad Center for Regenerative Medicine and Stem Cell Research, University of Southern CA Keck School of Medicine, Los Angeles, CA, USA

${ }^{4}$ Dept of Pathology and Human Anatomy, Loma Linda University School of Medicine, Loma Linda, CA, USA

${ }^{5}$ Dept of Anatomy and Embryology, Leiden University Medical Center, Leiden, Netherlands

\begin{abstract}
Aims: Human embryonic stem cell-derived cardiomyocytes (hESC-CMs) or mesenchymal stem cells (MSCs) facilitate post-infarct recovery, but the potential benefit of combination therapy using MSCs and hESC-CMs has not been examined. Our objective was to define the gene expression changes in donor and host-derived cells that are induced in vivo after co-transplantation of cardiomyocytes with and without mesenchymal stem cells expressing the prosurvival gene heme oxygenase 1.

Methods and results: Human MSCs were engineered to over-express heme oxygenase-1 (HO-1) following lentiviral vector-mediated transduction. Athymic nude rats were subjected to myocardial infarction and received hESC-CMs alone, hESC-CMs plus human MSCs, hESC-CMs plus MSCs overexpressing HO-1, or saline. Real time PCR identified gene expression changes. Cardiac function was assessed by angiography. Co-transplantation of unmodified MSCs plus hESC-CMs elevated CXCR4, HGF, and IGF expression over levels induced by injection of hESC-derived cardiomyocytes alone. In animals co-transplanted with MSC over-expressing HO-1, the expression of these genes was further elevated. Gene expression levels of VEGF, TGF- $\beta$, CCL2, SMAD7, STAT3 and cardiomyocyte transcription factors were highest in the HO-1 MSC plus hESC-CM group at 30 days. Human CD31+, CD34+, isl-1+, NXK2.5 and c-kit+ transcripts were elevated. Rodent genes encoding NKX2.5, troponin T and CD31 were elevated and cell cycle genes were induced. Ejection fraction improved by six to seven percent.
\end{abstract}

Conclusions: Co-administration of HO-1 MSCs plus hESC-CMs increased expression of pro-survival and angiogenesis-promoting genes in human cells and transcripts of cardiac and endothelial cell markers in rodent cells, consistent with activation of tissue repair in both transplanted hESC-CMs and the host heart.

Keywords: Cardiomyocyte; Human embryonic stem cells; Myocardial infarction; Mesenchymal stem cells; Heme oxygenase 1

Abbreviations: Heme oxygenase 1: HO-1; Human embryonic stem cell-derived cardiomyocytes: hESC-CM; Mesenchymal stem cells: MSC; Heme oxygenase 1 over-expressing mesenchymal stem cells: HO-1 MSC; Lentiviral vector backbone: pCLS

\section{Introduction}

Stem cell- based therapies for the treatment of heart failure are continually under modification to address the problems of insufficient stem cell retention and limited recruitment and/or activation of endogenous progenitors [1-3]. Early cardiovascular progenitors that differentiate into cardiac myocytes, endothelial cells and smooth muscle cells, when administered alone are insufficient for long-term regeneration of damaged cardiac tissue. Genetic engineering has been used as an approach to facilitate cell survival by over-expressing cytoprotective genes such as $\mathrm{AKT}^{4}$ or heme oxygenase 1 in mesenchymal stem cells [5-7]. This procedure improves cardiac function, but benefits derived from administration of genetically modified cells alone, or treatment with stem cells in combination with exogenous cytokines and/or anti-apoptotic cocktails [8-10] fall short when examined carefully for long-term reversal of cardiac remodeling accompanied by cardiac regeneration. Recently, promising results have been obtained using combination cell therapy [11]. Cardiovascular progenitors and epicardium derived cells, delivered together, were more beneficial than treatment with either cell type alone [11]. Our experimental objective, therefore, was to test the hypothesis that combined stem cell therapy using mesenchymal stem cells over-expressing HO-1 and cardiovascular stem cells derived from human embryonic stem cells could induce gene expression changes that promote paracrine and regenerative functions that may benefit stem cell therapy.

The role of mesenchymal stem cells in cell-based treatment strategies is generally agreed to be the secretion of factors including HGF, SDF-1, or VEGF that function to promote neovascularization in the damaged heart [12-14]. Endogenous circulating endothelial progenitor cells are further mobilized by over-expression of heme oxygenase 1 [15]. The beneficial effects can also be manifest by administration of $\mathrm{HO}-1$ over-expressing adenoviral vectors $[6,13,16-18]$. HO-1 initially gained recognition for its cytoprotective function in the allotransplant setting [19] and later for its beneficial anti-apoptotic effects in the ischemic environment of the heart post- infarct. The beneficial effects of HO-1

*Corresponding author: Mary Kearns-Jonker, Dept of Pathology and Human Anatomy, Loma Linda University School of Medicine, Loma Linda, CA, USA, E-mail: mkearnsjonker@llu.edu

Received April 30, 2012; Accepted June 05, 2012; Published June 07, 2012

Citation: Kearns-Jonker M, Dai W, Gunthart M, Fuentes T, Yeh HY, et al. (2012) Genetically Engineered Mesenchymal Stem Cells Influence Gene Expression in Donor Cardiomyocytes and the Recipient Heart. J Stem Cell Res Ther S1:005. doi:10.4172/2157-7633.S1-005

Copyright: (c) 2012 Kearns-Jonker M, et al. This is an open-access article distributed under the terms of the Creative Commons Attribution License, which permits unrestricted use, distribution, and reproduction in any medium, provided the original author and source are credited. 
have largely been attributed to carbon monoxide [14], a by-product produced when HO- 1 catalyzes the breakdown of heme into biliverdin, carbon monoxide and free iron. It has now been shown that the benefits of HO-1 for cardiovascular stem cell transplantation include a well-documented effect on angiogenesis $[16,20]$. SDF-1 promotes endothelial cell recruitment by a heme oxygenase 1 dependent mechanism [17].

Although upregulation of heme oxygenase 1 has been a component of several strategies designed to facilitate cardiovascular repair, our study is unique in that we examined the functional effect of cotransplantation of mesenchymal stem cells over-expressing HO-1 in combination with early cardiovascular progenitors derived from human embryonic stem cells. This report defines the sequential gene expression changes that contribute to a paracrine effect in vivo that can be enhanced and modulated by gene transfer of a cytoprotective molecule co-administered with a cell type capable of regeneration.

\section{Methods}

\section{Human embyonic stem cell culture and differentiation}

The human embryonic stem cell line hES-3 was maintained in our laboratory. The cells were differentiated into cardiomyocytes after co-culture on END-2 cells [21-22] or after differentiation from embryoid bodies [23]. Beating cells were dissected, dissociated and injected directly into the heart of athymic nude rats one week following myocardial infarction. This study was approved by the Human Embryonic Stem Cell Research Oversight Committee at Childrens Hospital Los Angeles.

\section{Cloning of the heme oxygenase 1 gene and lentiviral vector -mediated expression}

The human heme oxygenase 1 gene was PCR amplified using primers hmox fwd CTC TCG AGC GTC CTC A and hmox rev ACT ATC AGA CAA TGT TGT, and sequenced. A BamHI linker was added to the $1.7 \mathrm{~kb}$ HO-1 gene which was cloned into the pCLS lentiviral vector backbone, kindly provided by Dr. Gregor von Levetzow at Children's Hospital Los Angeles. The pCLS lentiviral vector is a derivative of pCL1, and included an FMDV-derived 2A self-cleaving peptide sequence in place of the internal ribosomal entry site upstream of an EGFP reporter gene [24]. Viral supernatant was generated by transfecting 293FT cells with pCLS-HO-1, the packaging plasmid and pMD2.G (VSV-G). Human MSC were kindly provided by Texas A\&M Health Science Center Institute for Regenerative Medicine. Transduction efficiencies of the MSC were reproducibly $40-60 \%$ as identified by FACS.

\section{Myocardial infarction and cardiovascular stem cell transplantation}

Female athymic nude rats (Harlan, Placentia, CA) at 5 weeks of age were anaesthetized with intraperitoneal ketamine $(75 \mathrm{mg} / \mathrm{Kg})$ and xylazine $(5 \mathrm{mg} / \mathrm{Kg})$, intubated and mechanically ventilated. The left coronary artery was ligated permanently. The rats were given buprenex $(0.001 \mathrm{mg} / 100 \mathrm{~g}$ body weight, twice daily) as an analgesic. One week later, four groups of 19 animals each received the following: Group 1 received two million hESC-derived, GFP labeled cardiomyocytes injected directly into the scar, Group 2: One million hESC-derived GFP labeled cardiomyocytes plus one million unmodified human mesenchymal stem cells derived from the bone marrow and labeled with Mito-red, Group 3: one million hESC-derived cardiomyocytes labeled with GFP plus one million mesenchymal stem cells transduced to over-express the human heme oxygenase 1 gene using a lentiviral vector and Group 4: saline control. Cardiac function was assessed by echocardiogram and angiogram $[25,26]$, cell retention was examined by histology, and gene expression changes occurring in vivo were analyzed by real time PCR. Fifteen animals per group were analyzed after 30 days; four animals per group were assessed at seven days after cell transplantation. The animals were euthanized by potassium chloride under general anesthesia. The Institutional Animal Care and Use Committee approved this study. Standards set by the Guide for the Care and Use of Laboratory Animals were followed.

\section{Gene expression analysis}

The infarct zone was dissected out and RNA was prepared using RNeasy minikits (Qiagen, Valencia, CA) or Trizol (Invitrogen, Carlsbad, CA). cDNA was synthesized using kits from SABiosciences or Applied BioSciences (Qiagen, Valencia, CA and Invitrogen, Carlsbad, CA respectively). Human array plates or TaqMan custom plates containing human and rat-specific primers pre-selected to identify our genes of interest were purchased from SABiosciences and Applied Biosciences. Individual PCR primers confirmed the expression of specific rat or human genes in cells isolated from the heart using laser capture microdissection. These samples were captured directly into tubes containing RT buffer and CDNA was prepared in the same tube. Real time PCR was performed on an ABI 7900 Fast Real time PCR machine [27,28]. Relative mRNA expression was normalized to GAPDH. Data was analyzed using SDSv2.4 software. Fold changes in gene expression were determined by comparing the $\mathrm{Ct}$ for each gene (in triplicate). A minimum of three biological replicates were run in each group before and after transplantation. Data was analyzed using the formula $2^{\Delta \Delta C t}$ where $\Delta \mathrm{Ct}=\mathrm{Ct}$ of our gene of interest- Ct of GAPDH. The results are shown + /- SEM.

\section{LV angiography}

At one and four weeks after stem cell transplantation, a catheter was inserted into the left jugular vein, under anaesthesia, and a nonionic contrast agent was administered to perform LV contrast angiography using a XiScan $1000 \mathrm{C}$-arm X ray system (XiTec, Inc., East Windsor, CT) [25]. Ejection fraction was determined using the formula $100 x[($ volume in diastole-volume in systole)/volume in diastole]. Stroke volumes and regional wall motion were also assessed.

\section{Regional wall motion}

The size of the paradoxical systolic bulging (dyskinesis) or akinetic motion was calculated by measuring the length of the total LV diastolic circumference, and circumferential length of the bulging or akinetic segment with computerized planimetry, expressed as a percent of total LV diastolic circumference [25].

\section{Hemodynamics}

A $2 \mathrm{~F}$ high-fidelity, catheter-tipped micromanometer (model SPR869, Millar Instruments, Inc, Houston, Texas) was used to record heart rate, aortic pressure (systolic, diastolic, mean), left ventricular systolic pressure, left ventricular end-diastolic pressure, and pressure volume loops [25]. Left ventricular $\mathrm{dP} / \mathrm{dT}$ (the change in ventricular pressure as a function of time) was also determined.

\section{Histological analysis}

Five micron sections were stained, scanned and digitized. The total LV circumference, infarct (scar) circumference, and non-infarcted wall circumference were measured. Infarct size was calculated as the percentage of the left ventricular circumference occupied by the scar. 
Wall thickness was measured. Myocardial infarct expansion index [29] was calculated by the formula: (LV cavity area/LV external area) $\mathrm{x}$ (septal thickness/infarct thickness).

\section{Statistical analysis}

The data are reported as the mean $+/$ - standard error and a Student's $\mathrm{t}$ test was performed for the gene expression studies. The LV fractional shortening, ejection fraction, hemodynamic data and histological data were compared by one-way ANOVA with subsequent Tukey's post hoc testing if appropriate. Statistically significant differences were $\mathrm{P}<0.05$.

\section{Results}

Transcripts of genes promoting cardiovascular regeneration and stem cell survival are enhanced by co-transplantation of human cardiovascular stem cells and mesenchymal stem cells over-expressing heme oxygenase 1

We cloned the human heme oxygenase 1 gene into the bicistronic lentiviral vector pCLS and transduced the human mesenchymal stem cells prior to transplantation. At 72 hours after transduction, flow cytometry demonstrated that $40-60 \%$ of the cells were transduced (Figure 1A). Heme oxygenase-1 levels were elevated 52 fold relative to HO-1 levels in non-transduced MSC in vitro and remained elevated in vivo at thirty days after transplantation. Transduced cells also demonstrated a 140 fold increase in transcripts for IL-10 and a 40 fold increase in transcripts for IL1-A (Figure 1B).

We used real time PCR to identify gene expression changes in the infarct zone of the heart at seven days after cotransplanting unmodified mesenchymal stem cells or HO-1 over-expressing MSC in combination with hESC-derived cardiomyocytes and compared the gene expression changes to those identified after transplantation of hES-derived cardiomyocytes alone (Figure 2). The addition of unmodified MSC was associated with a 4 fold increase in IGF1, a cytokine known to activate the PI3K/AKT pathway that leads to improved stem cell survival $[30,31]$. HO-1 over-expression provided additional benefit as shown by an 8 fold increase in IGF1 expression over cardiomyocytes alone (Figure 2). The PI3K/AKT pathway can also be activated by HGF [12] which was elevated 1.5 fold over levels induced by cardiomyocytes alone. The SDF-1/ CXCR4 axis was activated in this model (11 -15 fold elevation of CXCR4), potentially contributing to improved recipient stem cell homing to the heart, improved human stem cell engraftment and better survival [31-36]. The addition of HO-1 further elevates the expression of these genes (Figure 2).

Considering the impact of HO-1 on the paracrine milieu of the heart, we then examined the progression of these changes between days 7 and 30 after transplantation of hES-derived cardiomyocytes plus transduced MSC over-expressing HO-1. As shown in Figure 3, the beneficial effects of HO- 1 were significant at $p<0.05$ by day 30 . Elevated levels of cardiac transcription factors such NKX2.5 were noted at this time. Induced chemokines and cytokines included a 5.4 fold increase in HGF, a four-fold increase in VEGF, a 3.7 fold increase in TGFB1, and a 5.3 fold elevation in the levels of CSF1. STAT3 levels were also significantly elevated. CCL2, CCL5, MYH6 and HO-1 transcripts were highly induced at day 30 (Figure 3). Gene expression levels are shown when compared across each of our experimental groups, relative to pre-transplant gene expression levels, in Table 1. Gene expression changes in the combined treatment group without HO-1 no longer provided added benefit, relative to cardiomyocytes alone, at day 30. In contrast, gene expression changes in the HO-1 group in vivo
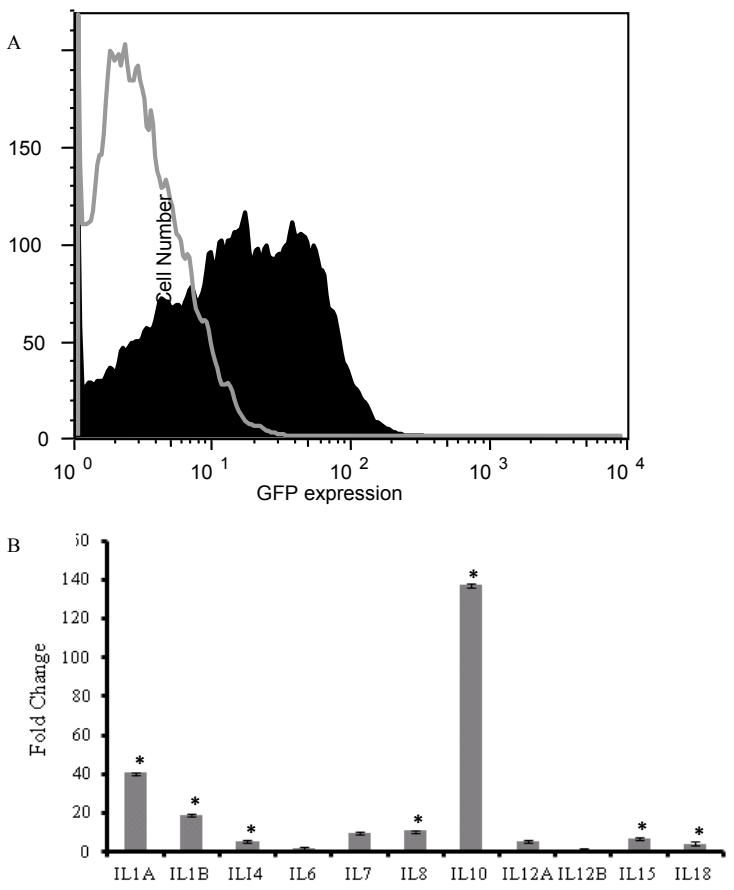

Figure 1: Transduction of mesenchymal stem cells with a lentiviral vector construct expressing heme oxygenase 1. Transduction efficiencies were examined by flow cytometry after every transduction, prior to cell transplantation, and ranged between $40-60 \%$ The clear tracing outlined in grey indicates the isotype control. The shaded black area represents GFP labeled cells expressing the HO-1 construct after transduction with this bicistronic vector $(A)$. Changes in cytokine expression were also identified by real time PCR. The graph shows the relative change in interleukin expression before and after mesenchymal stem cells were transduced to express heme oxygenase 1 . IL-10 and IL-1A levels were elevated when $\mathrm{HO}-1$ was over-expressed in mesenchymal stem cells (B). Data shown represent three independent experiments $+/$ - standard errors. Asterisks indicate statistical significance at $p<0.05$.

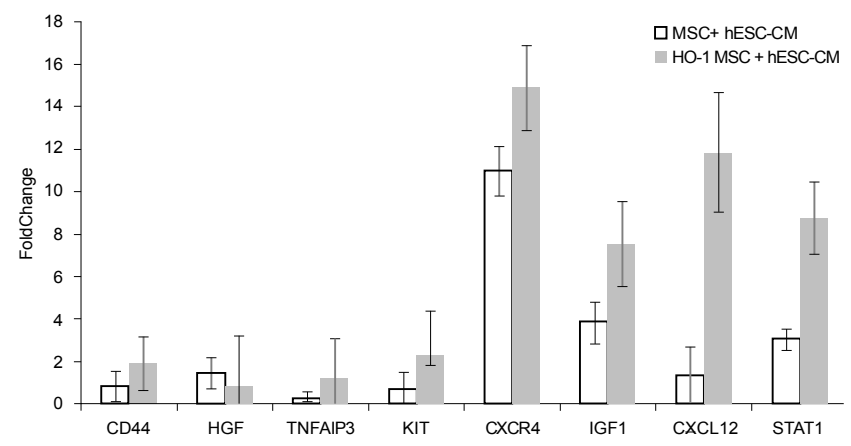

Figure 2: Gene expression changes in the heart in vivo at day 7 after transplantation of MSC plus human embryonic stem cell-derived cardiomyocytes (MSC+ hESC-CM), with and without heme oxygenase 1(HO-1), shown as fold changes relative to the in vivo group transplanted with hESC-CM alone. Real time PCR was used to identify changes in gene expression. Data are shown + - standard errors.

included highly elevated levels of thirty two different genes (Figures 3,4 and Table 1), some shown by others to independently benefit cardiovascular stem cell-mediated cardiovascular repair, some newly identified. Transcript levels for early cardiovascular stem cells (isl-1) [37] and elevated levels of CD34 [38-39] c-kit, Mesp-1 and NKX2.5 (Figure 4) suggest the potential for cardiovascular regeneration beyond 
Citation: Kearns-Jonker M, Dai W, Gunthart M, Fuentes T, Yeh HY, et al. (2012) Genetically Engineered Mesenchymal Stem Cells Influence Gene Expression in Donor Cardiomyocytes and the Recipient Heart. J Stem Cell Res Ther S1:005. doi:10.4172/2157-7633.S1-005

Page 4 of 8

the 30 day timepoint at which we concluded this study. Elevated VEGF levels may contribute to the well-characterized changes in angiogenesis that have been reported when HO-1 is over-expressed in the heart after myocardial infarction [13,40-41]. The prosurvival gene BCL2 is highly elevated in this model (Table 1) [42-43], and transcripts for elevated levels of the prosurvival genes HO-1 and TNFAIP3 [44] continued to be expressed at 30 days after transplantation in vivo.

HO-1 over-expression in mesenchymal stem cells introduced for cardiovascular repair promotes activation of host-derived trancripts in the heart

Primers designed to identify rodent CD31 and rodent Troponin $\mathrm{T}$ expressing cells were used in a real time PCR assay to identify recruitment of rodent cells into the heart. Rodent CD31 expression, identified within the infarct area of the heart at 30 days after transplantation and normalized to rat GAPDH, was four fold higher after co-transplantation of MSC over-expressing HO-1 and hESderived cardiomyocytes compared with animals transplanted with cardiomyocytes alone $(\mathrm{p}=0.007)$ (Figure 5). Transcripts for rodent cardiomyocytes expressing TropT were elevated 12 fold over levels achieved by human ES-derived cardiomyocyte stem cell transplantation alone.

Transcripts for rodent cell cycle regulatory genes CCND1, cyclins E, A2, Cdk2 and Cdk4 were elevated 2-16 fold compared to their expression level after treatment with cardiomyocytes alone (Figure 5).
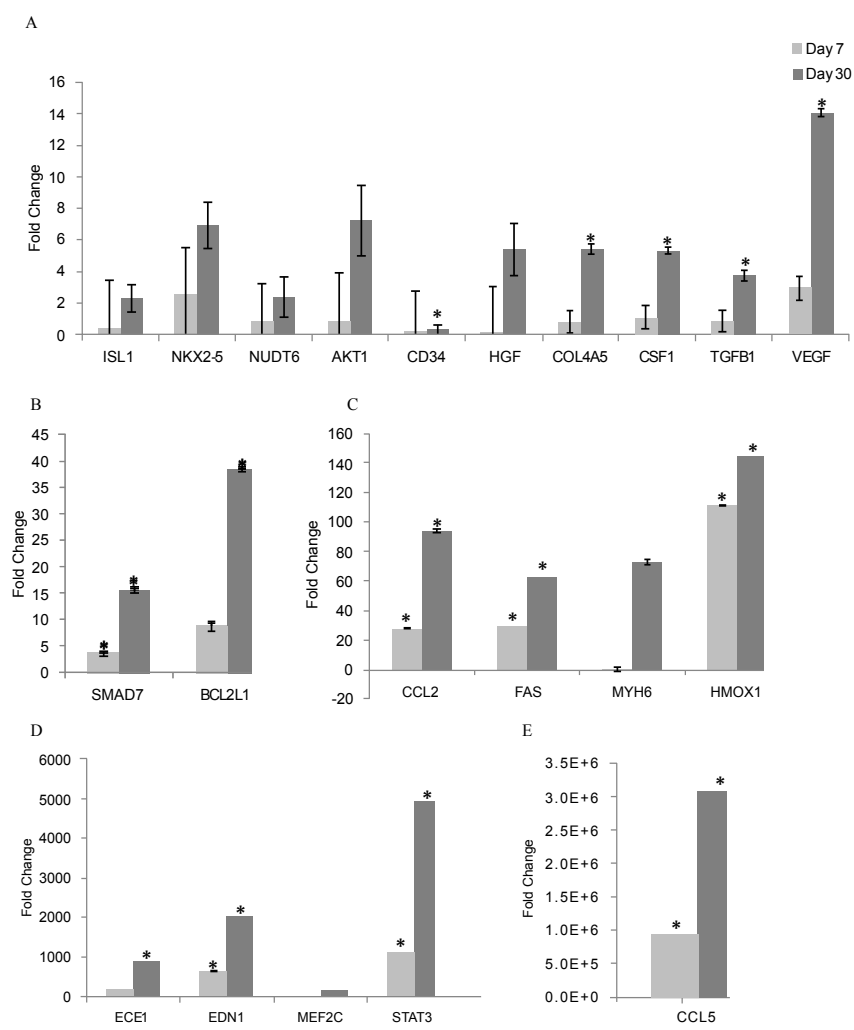

Figure 3: Gene expression changes in the heart within the HO-1-MSC $+\mathrm{hESC}-\mathrm{CM}$ transplanted group were more pronounced at day $\mathbf{3 0}$ when compared with day 7 . Real time PCR was used to identify changes in gene expression. Fold changes are shown when calculated relative to gene expression after transplantation of hESC-CM alone at the corresponding timepoint. Data are shown $+/$ - standard errors, asterisks identify gene expression changes that are significant at $p<0.05$.

\begin{tabular}{|c|c|c|c|c|}
\hline & Gene & $\begin{array}{l}\text { Fold change } \\
\text { cardiomyocytes } \\
\text { alone }{ }^{* *}\end{array}$ & $\begin{array}{l}\text { Fold change } \\
\text { cardiomyocytes } \\
+\mathrm{MSC}^{* *}\end{array}$ & $\begin{array}{c}\text { Fold change } \\
\text { cardiomyocytes } \\
\text { HO-1+MSC }\end{array}$ \\
\hline $\begin{array}{c}\text { B cell } \\
\text { lymphoma } 2\end{array}$ & BCL2 & 4642 & 3759 & 15,592 \\
\hline $\begin{array}{l}\text { Bcl-2-like } \\
\text { protein } 1\end{array}$ & BCL2L1 & 12 & 9 & 39 \\
\hline $\begin{array}{c}\text { Chemokine } \\
\text { (C-C motif) } \\
\text { ligand } 2\end{array}$ & CCL2 & 6 & 0.4 & 94 \\
\hline $\begin{array}{c}\text { Chemokine } \\
\text { (C-C motif) } \\
\text { ligand } 5\end{array}$ & CCL5 & 391,549 & $1,334,310$ & $3,097,523$ \\
\hline $\begin{array}{l}\text { Hematopoietic } \\
\text { progenitor cell } \\
\text { antigen CD34 }\end{array}$ & CD34 & 3.9 & 0.2 & 18 \\
\hline $\begin{array}{c}\text { CD68 } \\
\text { molecule }\end{array}$ & CD68 & 7 & 0.4 & 31 \\
\hline $\begin{array}{l}\text { Collagen, type } \\
\text { IV, alpha } 5\end{array}$ & COL4A5 & 7 & 0.02 & 5 \\
\hline $\begin{array}{l}\text { Colony } \\
\text { stimulating } \\
\text { factor } 1\end{array}$ & CSF1 & 1 & 0.1 & 5 \\
\hline $\begin{array}{l}\text { Endothelin } \\
\text { converting } \\
\text { enzyme } 1\end{array}$ & ECE1 & 545 & 550 & 906 \\
\hline Endothelin 1 & EDN1 & 529 & 640 & 2030 \\
\hline $\begin{array}{l}\text { Fas (TNF } \\
\text { receptor } \\
\text { superfamily } \\
\text { member 6) }\end{array}$ & FAS & 8 & 0.5 & 63 \\
\hline Fibronectin 1 & FN1 & 1 & 0.1 & 9 \\
\hline $\begin{array}{c}\text { Heme } \\
\text { oxygenase } 1\end{array}$ & HMOX1 & 8 & 13 & 145 \\
\hline $\begin{array}{c}\text { Mothers } \\
\text { against DPP } \\
\text { homolog } 8\end{array}$ & SMAD7 & 9 & 8 & 16 \\
\hline $\begin{array}{l}\text { Transforming } \\
\text { growth factor, } \\
\text { beta } 1\end{array}$ & TGFB1 & 1 & 0.6 & 4 \\
\hline $\begin{array}{c}\text { Vascular } \\
\text { endothelial } \\
\text { growth factor } \\
\text { A }\end{array}$ & VEGF & 7 & 0.02 & 14 \\
\hline
\end{tabular}

**Gene expression changes are shown relative to pre-transplant levels in cardiovascular progenitors. Fold changes are all significant at $p<0.05$ except CSF1, FN1, TGF 31 and VEGF in the cardiomyocyte alone group

Table 1: Gene Expression Changes at day 30 after Transplantation of hESCderived Cardiomyocytes, MSC + Cardiomyocytes or HO-1 MSC + Cardiomyocytes Post Infarction.

The cardiovascular transcription factor NKX2.5 was elevated in both donor and host-derived cells ( $\mathrm{p}=0.019)$ (Figures 4 and 5). Transcripts for genes encoding bcl2, IGF- 1 and IL-1 $\beta$, known to promote cell cycle activity, were elevated in the HO-1 co-transplant group. The ability to promote cell cycle activity may prove to be a beneficial effect achieved by combination cell therapy. These results support the concept that changes in receptors such as CCL2, CCL5, and CXCR4 combined with the changes in the cytokine/chemokine milieu associated with heme oxygenase 1 levels enhance recruitment/activation of host-derived cells in the heart.

\section{Stem cell treatment reduces infarct size and increases scar thickness}

Scars were thicker after stem cell treatment in all groups examined, 
compared with controls, however the favorable trends in infarct size and scar thickness were not statistically significant (Figure 6, Table 2). The expansion index was significantly higher in controls compared with stem cell treated groups $(\mathrm{p}=0.0039)$. Left ventricular akinesis and dyskinesis, assessed by left ventriculogram, was more pronounced in controls ( $\mathrm{p}=0.056)$ (Table 2). The finding that stem cell treatment significantly reduced left ventricular expansion index suggests that cell therapy may reduce left ventricular remodeling after permanent coronary artery occlusion. Other trends (infarct size, scar thickness, akinesis and dyskinesis, and fractional shortening) suggested that the treatment was beneficial.

\section{Stem cell treatment improves ejection fraction at four weeks}

The ejection fraction was significantly improved after stem cell treatment in all experimental groups compared to controls after 4 weeks (Figure 7). By contrast left ventriculogram, the ejection fraction in sham, non-infarcted rat hearts was $78.1 \pm 1.8 \%(n=5)$. The $L V$ ejection fraction (LVEF) after treatment with stem cells was significantly higher than controls (hESC-CMs: 67.6 +/- 1.4\%; hESC-CMs + MSCs: $67.2+/$ 1.6\%; hESC-CMs + HO-1 MSCs: $66.3+/-1.7 \%$ vs. $60.6+/-1.2 \%$ in controls, $\mathrm{p}=0.0022$ ). Heart rate, systolic blood pressure, diastolic blood pressure, positive $\mathrm{dp} / \mathrm{dt}$, negative $\mathrm{dp} / \mathrm{dt}$, and $\mathrm{LV}$ end systolic pressure were comparable in all groups (supplemental data). Irrespective of the nature of the cell therapy, stem cell treatment was found to benefit left ventricular function.

\section{Discussion}

Our study has demonstrated that co-administration of HO-1 MSCs plus hESC-CMs increased expression of pro-survival and angiogenesispromoting genes in human cells, transcripts of cardiac and endothelial cell markers in rodent cells, and transcripts for cell cycle regulatory genes in the rodent heart. These results are consistent with activation of tissue repair in both transplanted hESC-CMs and the host heart. We further defined several factors and chemokines expressed in vivo during this process.

Heme oxygenase 1 has well-documented anti-inflammatory and cytoprotective functions. HO-1 catalyzes the degradation of heme

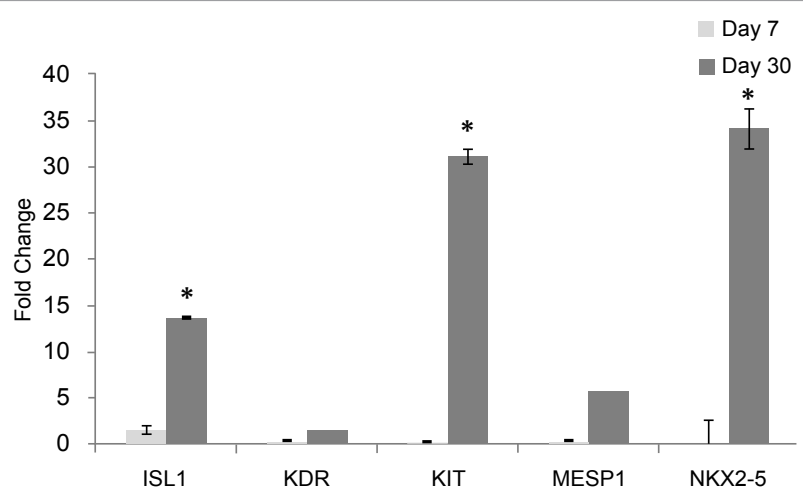

Figure 4: Transcripts of genes expressed in human cardiovascular progenitors were elevated at day 30 when compared with day 7 in the HO-1 MSC+ hESC-CM group. Gene expression changes shown were identified using real time PCR in the group of animals transplanted with human embryonic stem cell-derived cardiomyocytes plus heme oxygenase 1 overexpressing mesenchymal stem cells. Fold changes were calculated relative to gene expression in the animals receiving cardiomyocytes alone at the corresponding timepoint in vivo. Data are shown $+/-$ standard errors. Asterisks indicate statistical significance at $p<0.05$
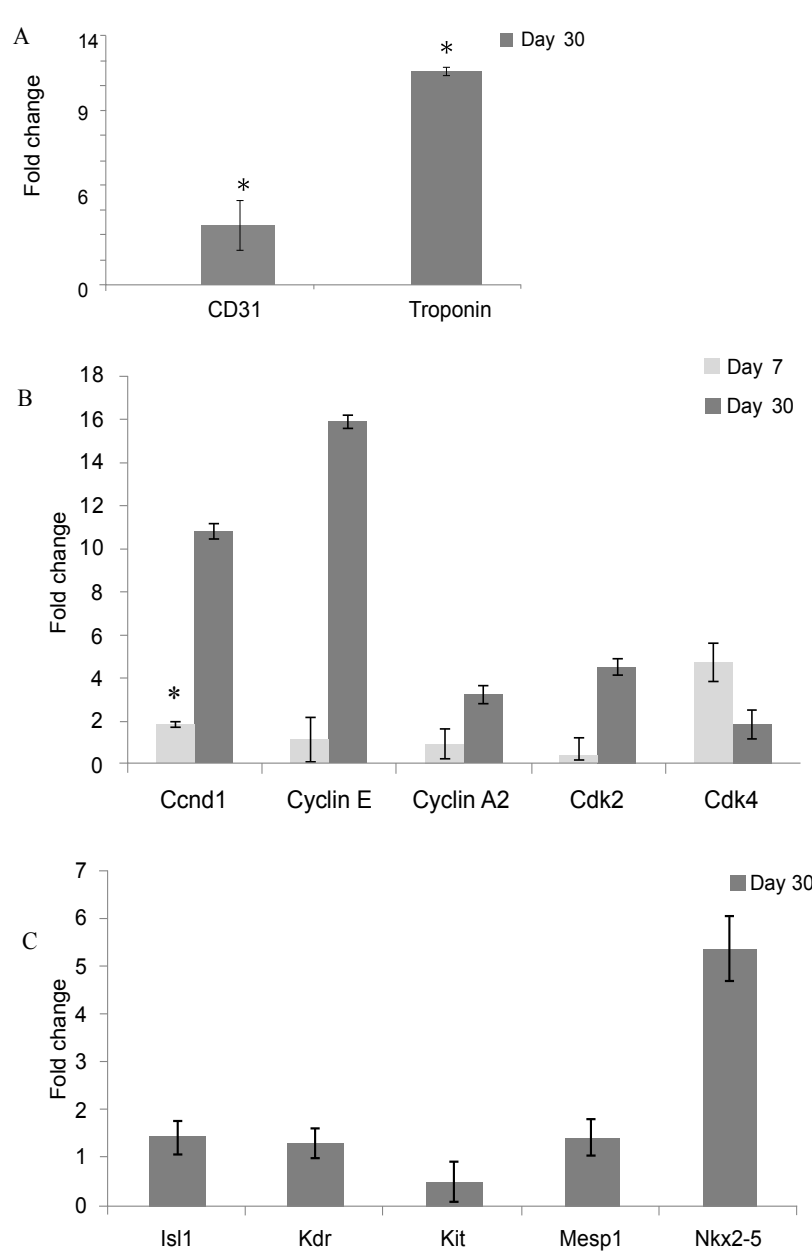

Figure 5: Gene expression changes identified in the recipient heart using rodent specific primers after stem cell transplantation. Laser capture microdissection was used to isolate cells from the infarct zone at 30 days after myocardial infarction. Real time PCR performed on the captured cells using rodent specific primers identified higher levels of rat CD31 and rat Troponin expressing cells in the human embryonic stem cell-derived cardiomyocyte plus $\mathrm{HO}-1 \mathrm{MSC}$ treated animals relative to animals treated with cardiomyocytes alone $(A)$. Rodent specific primers were used to demonstrate elevated expression of rodent cell cycle associated genes (B) and the rodent cardiovascular progenitors were identified with rodent-specific primers in the infarct zone at 30 days after transplantation (C). Data are shown $+/-$ standard errors, * values indicate significance at $p<0.05$

into biliverdin, carbon monoxide and free iron, by-products with anti-oxidant and cytoprotective effects. Additional benefits of HO-1 over-expression in the heart, as reported by others, include enhanced neovascularization, a reduction in myocardial wall thinning, collagen deposition and decreased inflammatory cell infiltration [12-20]. These beneficial effects were demonstrated after direct administration of HO-1 into the myocardium or over-expression of $\mathrm{HO}-1$ in mesenchymal stem cells transplanted into the heart [6,7]. HO-1 reduces superoxidase dismutase levels and elevates the expression of genes with pro-survival functions such as Bcl2 $[42,43]$ and IL-10 [6,12]. These findings were confirmed in our model. Neovascularization is enhanced when HO-1 is over-expressed and is associated with endothelial cell progenitor mobilization [20]. Carbon monoxide, a byproduct of HO-1, is responsible for many but not all, of the benefits of HO-1 treatment [14]. CO can attenuate apoptosis and alleviate LV remodeling [16]. Lakkisto et al. [14] have shown that CO increases c-kit+ progenitors 
in the infarct zone. Elevated levels of HIF-1a, SDF-1 $\alpha$, and VEGF-B were noted in the infarct area after CO treatment. In the heart, VEGF and SDF-1 induced after HO-1 treatment promote recruitment of circulating progenitor c-kit + and CD34+ cells [13,34]. The SDF1:CXCR4 axis may be one mechanism by which cardiovascular progenitors are recruited into the heart $[35,36]$. SDF-1 is produced by mesenchymal stem cells and HO-1 over-expression prolongs their survival. At present, we cannot determine whether the host-derived cardiovascular progenitors originate from endogenous stem cells in the heart or are recruited from other sites such as the bone marrow.

Lineage mapping has recently shown that exogenously delivered, bone marrow derived c-kit+ cells can stimulate endogenous cardiac progenitors post-infarction [46]. The extent to which progenitor cells can be activated by various mechanisms and their contribution to repair has yet to be determined. This issue is significant due to the limited survival of cells introduced into the ischemic environment of the heart. In large animals such as pigs, transplantation of bone marrow-derived mesenchymal stem cells stimulates c-kit+ cardiac stem cell recruitment and proliferation, an effect not seen after injection of MSC-conditioned

\begin{tabular}{|c|c|c|c|c|}
\hline \multicolumn{5}{|c|}{ Histological parameters } \\
\hline Group & $\begin{array}{c}\text { Infarct size } \\
\text { (percent) }\end{array}$ & $\begin{array}{c}\text { Scar thickness } \\
(\mathrm{mm})\end{array}$ & $\begin{array}{c}\text { Expansion } \\
\text { index* }\end{array}$ & $\begin{array}{c}\text { Akinesis \& } \\
\text { dyskinesis (\%) }\end{array}$ \\
\hline hESC-CM & $28.7 \pm 5.5$ & $1.3 \pm 0.21$ & $0.27 \pm 0.11$ & $8.96 \pm 1.9$ \\
\hline MSC+CM & $35.7 \pm 4.1$ & $1.52 \pm 0.28$ & $0.31 \pm 0.08$ & $8.37 \pm 1.67$ \\
\hline $\begin{array}{c}\text { HO-1 } \\
\text { MSC+CM }\end{array}$ & $30.8 \pm 4.2$ & $1.25 \pm 0.14$ & $0.36 \pm 0.07$ & $4.57 \pm 1.00$ \\
\hline saline & $42.5 \pm 2.8$ & $0.71 \pm 0.04$ & $0.71 \pm 0.05$ & $10.73 \pm 1.76$ \\
\hline p value & 0.166 & 0.091 & 0.0039 & 0.056 \\
\hline
\end{tabular}

*For expansion index, there was a significant group effect by ANOVA $(p=0.0039)$ Tukey's test showed that the expansion index was significantly higher in the control group versus each of the 3 cell-treated groups $(p<0.05)$.

Table 2: Infarct Size and Cardiac Function Four Weeks After Stem Cell-Based Therapy.

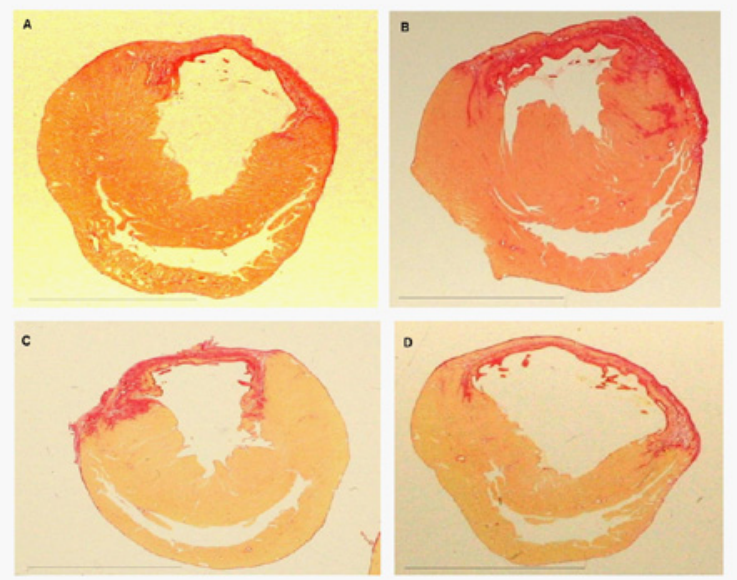

Figure 6: Histological analysis of the infarcted hearts after stem cel transplantation compared with controls. Rat hearts stained with picrosirius red after myocardial infarction (A) hESC-CMs (B) hESC-CMs + MSCs (C) hESC-CMs + MSCs over-expressing HO-1 and (D) saline. The scar (picrosirius red area which is positive for collagen) in the control group (D) is thin and appears stretched while the scars in the three cell-treated groups $(A, B, C)$ were thicker and less stretched.

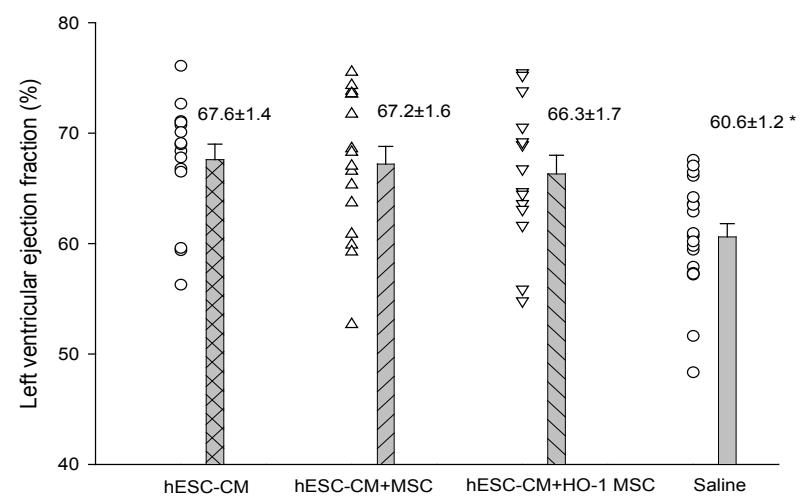

Figure 7: Ejection fraction was improved by stem cell transplantation Left ventricular ejection fraction in the cell-treated groups was significantly higher than that of the saline treated control group. * A significant difference was noted between the saline group vs. human embryonic stem cell-derived cardiomyocytes (hESC-CM), the saline group vs. hESC-CM plus MSC, and between saline injected controls and animals injected with hESC+HO-1 MSC. Significance by ANOVA was $p=0.0022, p<0.05$ by Tukey's test.

media [38]. Cell-cell coupling between transplanted MSCs and endogenous CSCs occurs in the pig, promoting the transport of factors that enhance stem cell survival. The number of NKX2.5 positive cells is elevated by co-culturing CSC and MSC in vitro and the number of c-kit positive cells was elevated in vivo in the pig. Elevated levels of NKX2.5 and c-kit transcripts were noted after co-transplantation in vivo in our model. Higher levels of gene expression for CD34 and isl-1 were detected after HO-1 over-expression in our study. This is perhaps due to co-localization or cell to cell communication between newly-introduced cells. The close proximity of pro-survival factors and chemokines may benefit stem cell survival, stem cell recruitment and regeneration.

In our model, co-transplantation of unmodified MSC plus cardiovascular progenitors was more beneficial than transplantation of cardiovascular progenitor cells alone. Co-transplantation elevated expression of factors promoting cardiac repair such as HGF and IGF1. Co-transplantation of MSC over-expressing HO-1 with cardiovascular progenitors enhanced the levels of NKX2.5 and CD34. SMAD7, a gene required for cardiac development and function [47], CCL5, a gene whose product plays a role in chemokine-mediated migration of stem cells [48] and IL-10, a gene whose product reduces left ventricular remodeling by activation of STAT3 were all elevated in the HO-1MSC plus hESC-CM group [49-50]. Induced gene expression levels of both donor and host-derived cardiovascular cells were higher at 30 days after HO-1MSC plus hESC-CM transplantation. The potential benefit to cardiovascular recovery over the long term when cardiovascular progenitors are actively differentiating from both donor and recipient sources is highly significant due to the known limitations in the numbers of cardiovascular stem cells that can be delivered.

The concept that complementary cell populations provide an added benefit over transplantation of a single cell population alone is not unprecedented. In a recent report by Winter et al. [11], a combination of adult human epicardium-derived cells and cardiomyocyte progenitors was more beneficial than single cell treatment in an ischemic heart model. The adult human epicardium-derived cells were intended to protect the myocardium and stimulate migration of resident cardiac progenitors by a paracrine effect when combined with progenitor cells. The factors secreted were not defined, however, the ejection fraction 
and stroke volume were significantly improved by combination cell therapy six weeks after transplantation. Based on our finding that changes in gene expression identifying both donor and host progenitors were activated at 30 days but not at 7 days after transplantation, it is conceivable that we may have detected a more pronounced functional benefit at a later time point. By histology, our qualitative and quantitative analysis showed that the average scar thickness was greater after cell treatment when compared to the saline group. The benefit of scar thickening as a positive phenomenon is reflected in the strong trend toward less akinesis and dyskinesis in the cell treated groups versus controls and was particularly prominent in the $\mathrm{HO}-1$ treated group. Further experimentation will provide additional insight into the long term functional effects of combination cell therapy and the mechanism by which donor and host-derived cardiovascular stem cells are activated in this model.

\section{Acknowledgement}

This work was supported by a grant from the National Heart, Lung and Blood Institute of the National Institutes of Health (grant number K18 HL092288-01) to MKJ.

\section{References}

1. Kearns-Jonker M, Dai W, Kloner RA (2010) Stem Cells for the Treatment of Heart Failure. Curr Opin Mol Ther 12: 432-441.

2. Mummery CL, Davis RP, Krieger JE (2010) Challenges in using stem cells for cardiac repair. Sci Transl Med 2: 27

3. Fernandes S, Naumova AV, Zhu WZ, Laflamme MA, Gold J, et al. (2010) Human embryonic stem cell-derived cardiomyocytes engraft but do not alter cardiac remodeling after chronic infarction in rats. J Mol Cell Cardiol 49: 941 949.

4. Gnecchi M, He H, Liang OD, Melo LG, Morello F, et al. (2005) Paracrine action accounts for marked protection of ischemic heart by Akt-modified mesenchymal stem cells. Nat Med 11: 367-368.

5. Tang YL, Tang Y, Zhang YC, Qian K, Shen L, et al. (2005) Improved graft mesenchymal stem cell survival in ischemic heart with a hypoxia-regulated heme-oxygenase 1 vector. J Am Coll Cardiol 46: 1339-1350.

6. Zeng B, Chen H, Zhu C, Ren X, Lin G, et al. (2008) Effects of combined mesenchymal stem cells and heme oxygenase-1 therapy on cardiac performance. Eur J Cardiothorac Surg 34: 850-856.

7. Zeng B, Lin G, Ren X, Zhang Y, Chen H (2010) Over-expression of HO-1 on mesenchymal stem cells promotes angiogenesis and improves myocardial function in infarcted myocardium. J Biomed Sci 17: 80.

8. Tsubokawa T, Yagi K, Nakanishi C, Zuka M, Nohara A, et al. (2010) Impact of anti-apoptotic and anti-oxidative effects of bone marrow mesenchymal stem cells with transient overexpression of heme oxygenase- 1 on myocardial ischemia. Am J Physiol Heart Circ Physiol 298: H1320-H1329.

9. Laflamme M, Chen KY, Naumova AV, Muskheli V, Fugate JA, et al. (2007) Cardiomyocytes derived from human embryonic stem cells in pro-survival factors enhance function of infarcted rat hearts. Nat Biotechnol 25: 1015-1024.

10. Okada H, Takemura G, Kosai K, Tsujimoto A, Esaki M, et al. (2009) Combined therapy with cardioprotective cytokine administration and antiapoptotic gene transfer in postinfarction heart failure. Am J Physiol Heart Circ Physiol 296 H616-H626.

11. Winter EM, van Oorschot AA, Hogers B, van der Graaf LM, Doevendans PA et al. (2009) A new direction for cardiac regeneration therapy: application of synergistically acting epicardium-derived cells and cardiomyocyte progenitor cells. Circ Heart Fail 2: 643-653.

12. Zeng B, Ren X, Lin G, Zhu C, Chen H, et al. (2008) Paracrine action of HO-1modified mesenchymal stem cells mediates cardiac protection and functional improvement. Cell Biol Int 32: 1256-1264.

13. Lin HH, Chen YH, Chang PF, Lee YT, Yet SF, et al. (2008) Heme oxygenase-1 promotes neovascularization in ischemic heart by coinduction of VEGF and SDF-1. J Mol Cell Cardiol 45: 44-55.

14. Lakkisto P, Kytö V, Forsten H, Siren JM, Segersvärd H, et al. (2010) Heme oxygenase-1 and carbon monoxide promote neovascularization after myocardial infarction by modulating the expression of HIF-1alpha, SDF-1alpha and VEGF-B. Eur J Pharmacol 635: 156-164.

15. Wu BJ, Midwinter RG, Cassano C, Beck K, Wang Y, et al. (2009) Heme oxygenase-1 increases endothelial progenitor cells. Arterioscler Thromb Vasc Biol 29: 1537-1542.

16. Wang G, Hamid T, Keith RJ, Zhou G, Partridge CR, et al. (2010) Cardioprotective and antiapoptotic effects of heme oxygenase-1 in the failing heart. Circulation 121: $1912-1925$

17. Lin HH, Chen YH, Yet SF, Chau LY (2009) After vascular injury, heme oxygenase-1/carbon monoxide enhances re-endothelialization via promoting mobilization of circulating endothelial progenitor cells. J Thromb Haemost 7 : 1401-1408.

18. Pachori AS, Smith A, McDonald P, Zhang L, Dzau VJ, et al. (2007) Heme oxygenase-1-induced protection against hypoxia/reoxygenation is dependent on biliverdin reductase and its interaction with $\mathrm{PI} 3 \mathrm{~K} / \mathrm{Akt}$ pathway. $\mathrm{J}$ Mol Cell Cardiol 43: 580-592.

19. Yamashita K, Ollinger R, McDaid J, Sakahama H, Wang H, et al. (2006) Heme oxygenase-1 is essential for and promotes tolerance to transplanted organs. FASEB J 20: 776-778.

20. Tongers J, Knapp JM, Korf M, Kempf T, Limbourg A, et al. (2008) Heme oxygenase promotes progenitor cell mobilization, neovascularization, and functional recovery after critical hindlimb ischaemia in mice. Cardiovasc Res 78: 294-300.

21. Passier R, Oostwaard DW, Snapper J, Kloots J, Hassink RJ, et al. (2005) Increased cardiomyocyte differentiation from human embryonic stem cells in serum-free cultures. Stem Cells 23: 772-780.

22. Mummery C, Ward-van Oostward D, Doevendans $P$, Spijker R, van den Brink S, et al. (2003) Differentiation of human embryonic stem cells to cardiomyocytes: role of coculture with visceral endoderm-like cells. Circulation 107: 2733-2740.

23. Kehat I, Khimovich L, Caspi O, Gepstein A, Shofti R, et al. (2004) Electromechanical integration of cardiomyocytes derived from human embryonic stem cells. Nat Biotechnol 22: 1282-1289.

24. von Levetzow C, Jiang X, Gwye Y, von Levetzow G, Hung L, et al. (2011) Modeling initiation of Ewing sarcoma in human neural crest cells. PLoS One 6: e19305.

25. Dai W, Hale S, Kloner RA (2007) Role of a paracrine action of mesenchyma stem cells in the improvement of left ventricular function after coronary artery occlusion in rats. Regen Med 2: 63-68.

26. Dai W, Hale SL, Martin BJ, Kuang JQ, Dow JS, et al. (2005) Allogeneic mesenchymal stem cell transplantation in postinfarcted rat myocardium. Shortand long- term effects. Circulation 112: 214-223.

27. Evans JM, Doki T, Fischer-Lougheed J, Davicioni E, Kearns-Jonker M (2006) Expression changes in tolerant murine cardiac allografts after gene therapy with a lentiviral vector expressing $\alpha 1,3$ galactosyltransferase. Transplant Proc 38: 3172-3180.

28. Doki T, Mello M, Mock D, Evans JM, Kearns-Jonker M (2008) Intragraft gene expression profile associated with the induction of tolerance. BMC Immunology 9: 5

29. Hochman JS, Choo H (1987) Limitation of myocardial infarct expansion by reperfusion independent of myocardial salvage. Circulation 75: 299-306.

30. Enoki C, Otani H, Sato D, Okada T, Hattori R, et al. (2010) Enhanced mesenchymal cell engraftment by IGF-1 improves left ventricular function in rats undergoing myocardial infarction. Int J Cardiol 138: 9-18.

31. Penn MS, Agarwal U (2010) IGF-1 and mechanisms of myocardial repair. Int J Cardiol 138: 1-2

32. Schober A, Karshovska E, Zernecke A, Weber C (2006) SDF-1alpha-mediated tissue repair by stem cells: a promising tool in cardiovascular medicine? Trend Cardiovasc Med 16: 103-108.

33. Yin $Q$, Jin $P$, Liu $X$, Wei $H$, Lin $X$, et al. (2011) SDF-1a inhibits hypoxia and serum deprivation-induced apoptosis in mesenchymal stem cells through PI3K Akt and ERK1/2 signaling pathways. Mol Biol Rep 38: 9-16.

34. Unzek S, Zhang M, Mal N, Mills WR, Laurita KR, et al. (2007) SDF-1 recruits cardiac stem cell-like cells that depolarize in vivo. Cell Transplant 16: 879-886. 
Citation: Kearns-Jonker M, Dai W, Gunthart M, Fuentes T, Yeh HY, et al. (2012) Genetically Engineered Mesenchymal Stem Cells Influence Gene Expression in Donor Cardiomyocytes and the Recipient Heart. J Stem Cell Res Ther S1:005. doi:10.4172/2157-7633.S1-005

35. Penn MS (2009) Importance of the SDF-1:CXCR4 axis in myocardial repair. Circ Res 104: 1133-1135.

36. Chiriac A, Terzic A, Park S, Ikeda Y, Faustino R, et al. (2010) SDF-1-enhanced cardiogenesis requires CXCR4 induction in pluripotent stem cells. J Cardiovasc Transl Res 3: 674-682.

37. Moretti A, Caron L, Nakano A, Lam JT, Bernshausen A, et al. (2006) Multipotent embryonic isl1+ progenitor cells lead to cardiac, smooth muscle, and endothelial cell diversification. Cell 127: 1151-1165.

38. Hatzistergos KE, Quevedo H, Oskouei BN, Hu Q, Feigenbaum GS, et al. (2010) Bone marrow mesenchymal stem cells stimulate cardiac stem cell proliferation and differentiation. Circ Res 107: 913-922.

39. Zaruba MM, Soonpa MM, Reuter S, Field LJ (2010) Cardiomyogenic potentia of c-kit+ expressing cells derived from neonatal and adult mouse hearts. Circulation 121: 1992-2000

40. Nourse MB, Halpin DE, Scatena M, Mortisen DJ, Tulloch N, et al. (2010) VEGF induces differentiation of functional endothelium from human embryonic stem cells. Arterioscler Thromb Vasc Biol 30: 80-89.

41. Lin HH, Lai SC, Chau LY (2011) Heme oxygenase-1/carbon monoxide induces vascular endothelial growth factor expression via p38 kinase-dependen activation of Sp1. J Biol Chem 286: 3829-3838.

42. Kitabayashi K, Siltanen A, Pätilä T, Mahar MA, Tikkanen I, et.al (2010) Bcl2 expression enhances myoblast sheet transplantation therapy for acute myocardial infarction. Cell Transplant 19: 573-588.

43. Kutschka I, Kolfidis T, Chen IY, von Degenfeld G, Zwierzchoniewska M, et al. (2006) Adenoviral human Bcl2 transgene expression attenuates early donor cell death after cardiomyoblast transplantation into ischemic rat hearts Circulation 114: I174-I180.

44. Souza Al, Felkin LE, McCormack AM, Holder A, Barton PJ, et al. (2005) Sequential expression of three known protective genes in cardiac biopsies after transplantation. Transplantation 79: 584-590.

45. Tang XL, Rokosh G, Sanganalmath SK, Yuan F, Sato H, et al. (2010) Intracoronary administration of cardiac progenitor cells alleviates left ventricula dysfunction in rats with a 30-day-old infarction. Circulation 121: 293-305.

46. Loffredo F, Steinhauser M, Gannon J, Lee RT (2011) Bone marrow-derived cell therapy stimulates endogenous cardiomyocyte progenitors and promotes cardiac repair. Cell Stem Cell 8: 389-398.

47. Chen $Q$, Chen $H$, Zheng D, Kuang C, Fang $H$, et al. (2009) Smad7 is required for the development and function of the heart. J Biol Chem 284: 292-300.

48. Kroeze KL, Jurgens WJ, Doulabi BZ, van Milligen FJ, Scheper RJ, et al. (2009) Chemokine-mediated migration of skin-derived stem cells: predominant role for CCL5/RANTES. J Invest Dermatol 129: 1569-1581.

49. Li JQ, Qi HZ, He ZJ, Hu W, Si ZZ, et al. (2009) Cytoprotective effects of human interleukin-10 gene transfer against necrosis and apoptosis induced by hepatic cold ischemia/reperfusion injury. J Surg Res 157: e71-e78.

50. Krishnamurthy P, Rajasingh J, Lambers E, Qin G, Losordo DW, et al. (2009) IL-10 inhibits inflammation and attenuates left ventricular remodeling after myocardial infarction via activation of STAT3 and suppression of HuR. Circ Res 104: e9-e18. 